\title{
Characterization of Oil Extracted from Two Varieties of Tiger Nut (Cyperus esculentus L.) Tubers
}

\author{
Aliyu Ahmad Warra ${ }^{1, ~ *, ~ L e y e ~ J o n a t h a n ~ B a b a t o l a ~}{ }^{2}$, Adedara Adejoju Omodolapo ${ }^{3}$, \\ Basiru Dende Ibraheem ${ }^{2}$ \\ ${ }^{1}$ Centre for Entrepreneurship Development, Federal University, Gusau, Nigeria \\ ${ }^{2}$ Department of Chemical Sciences, Biochemistry Unit, Joseph Ayo Babalola University, Ikeji-Arakeji, Nigeria \\ ${ }^{3}$ Chemistry Department, Federal University of Technology, Akure, Nigeria
}

Email address:

aliyuwarra@yahoo.com (A. A. Warra)

*Corresponding author

\section{To cite this article:}

Aliyu Ahmad Warra, Leye Jonathan Babatola, Adedara Adejoju Omodolapo, Basiru Dende Ibraheem. Characterization of Oil Extracted from Two Varieties of Tiger Nut (Cyperus esculentus L.) Tubers. American Journal of Heterocyclic Chemistry. Vol. 3, No. 3, 2017 , pp. $28-36$. doi: $10.11648 /$ j.ajhc. 20170303.12

Received: May 16, 2017; Accepted: July 12, 2017; Published: July 27, 2017

\begin{abstract}
The qualitative determination of fatty acids from hexane extract of two varieties of Cyperus esculentus L. tuber oil using Gas Chromatography-Mass Spectrometry (GC-MS) analysis revealed the following fatty acids; palmitic acid, steric acid, Margaric acid, elaidic acid, oleic acid, erucic acid, behenic acid. and arachidic acid. For the Fourier Transform Infra-Red (FTIR) analysis, bands of $3469.09 \mathrm{~cm}^{-1}, 3463.3 \mathrm{~cm}^{-1}$, sharp bands at $2867.28 \mathrm{~cm}^{-1}, 2037.86 \mathrm{~cm}^{-1}$ and $2866.32 \mathrm{~cm}^{-1}$ asymmetrical and symmetrical modes of vibration of $-\mathrm{CH}_{2^{-}}$, strong band $1742.74 \mathrm{~cm}^{-1}$ and $1743.71 \mathrm{~cm}^{-1}$ due to ester carbonyl functional group of the triacylglycerols, bending vibrations of the $\mathrm{CH}_{2}$ and $\mathrm{CH}_{3}$ aliphatic groups, (C-CO-O- and $\mathrm{O}_{-} \mathrm{CH}_{2}-\mathrm{C}$ ) and the inplanebending vibration of $\mathrm{CH}$ cis-olefinic groups seen at $1449.55 \mathrm{~cm}^{-1}, 1364 \mathrm{~cm}^{-1}$ and $1450.52 \mathrm{~cm}^{-1}, 1365.65$, and $1450.52 \mathrm{~cm}^{-1}$, $1365.65 \mathrm{~cm}^{-1}$, vibration frequency at, $1166.97 \mathrm{~cm}^{-1}$ finger print of the stretching vibration of the C-O ester group, frequencies of the in-and out-of plane rocking of the cis-olefinic $\mathrm{CH}_{2}$ group at $718.51 \mathrm{~cm}^{-1}$ were observed for the brown and yellow tiger nut tubers oil respectively. The results were in favour of the utilization of the two varieties of Tiger nut (Cyperus esculentus $\mathrm{L}$.) tubers oil in cosmetics, polymer and food industries.
\end{abstract}

Keywords: Tiger Nut Tuber Oil, GC-MS, FT-IR, Fatty Acids, Cosmetics, Polymers, Food

\section{Introduction}

Tiger nut is an underutilized crop of the family Cyperaceae, which produces rhizomes from the base and tubers that are somewhat spherical. Pollination is by wind. Young tubers are white, while older tubers are covered by a yellow outer membrane; they are usually found within six inches of the ground surface. Vegetative colonies of its plants are often produced from the tubers and their rhizomes. The derivatives and benefits of Cyperus esculentus Lativum as a plant was reported [1]. It has many other names like; Chufa, Zulu nuts, yellow nut grass, and ground almond, edible rush and rush nuts [2]. In Nigeria, some of its native names include 'Aya' in Hausa, 'Imumu' in Yoruba, 'Ofio' or 'akihausa' in Igbo [3]. Oil is a One of the major source of essential mineral content in the diets of common people in
Africa. Edible and Non-edible Oil Potentials of Tiger Nut (Cyperus esculentus) Grown in Nigeria was investigated [4]. Quality Characteristics of oil from two varieties of Cyperus esculentus L. tubers was physicochemical determined [5]. Despite its high nutritional value, tiger nut oil is hardly used in food industries compared to other vegetable oils such as olive and peanut oil. However, its benefits are increasingly being recognized, including its stability and similarity to olive oil in particular. Based on the available data, tiger nut oil has been established as an oil of good nutritional value which may be exploited to the great benefit of growers, processors and dealers of the tuber [6]. Evaluation of the physicochemical properties and fatty acids composition of tiger nut (Cyperus. esculentus) tuber oil in comparison with olive, maize, sunflower and soybean oils was reported. It showed that Tiger nut tuber oil can replace imported olive, 
maize, sunflower and / or soy bean oils in foods to face the high consumption of edible oils in Egypt [7]. Safety profile and antioxidant activity of fatty hydroxamic acid from underutilized seed oil of Cyperus esculentus was evaluated [8]. Physico-Chemical Characterization of Vegetable Oil and Defatted Meal from Two Varieties of Cyperus esculentus from Benin was reported [9]. This research is aimed at GCMS and FT-IR analysis of oil from Brown and Yellow Cyperus esculentus tubers and justify their industrial potential for cosmetics, polymer and food preparations.

\section{Experimental}

\subsection{Sample Collection, Identification and Preparation}

The dried tubers of the two varieties of Cyperus esculentus L. were crushed into powder using mortar and pestle and were stored in a plastic container prior to oil extraction.

\subsection{Oil Extraction Procedure}

The hexane extract was obtained by complete extraction using the Soxhlet extractor (GG-17, SHUNIU). The $50 \mathrm{~g}$ of each powdered sample was put into a porous thimble and placed in a Soxhlet extractor, using $150 \mathrm{~cm} 3$ of n-hexane (with boiling point of $40-60^{\circ} \mathrm{C}$ ) as extracting solvent for 6 hours repeatedly until required quantity was obtained. The oil was obtained after evaporation using Water bath at $70^{\circ} \mathrm{C}$ to remove the excess solvent from the extracted oil. The oil was then stored in refrigerator prior to GC-MS analysis.

\subsection{FT-IR Analysis}

The analysis of the fatty acids in the Cyperusesculentus L. tuber oilsample was done at National Institute of Chemical Technology (NARICT), Zaria, Nigeria. Shimadzu 8400s Fourier Transformed Infra-red spectrophotometer was used.

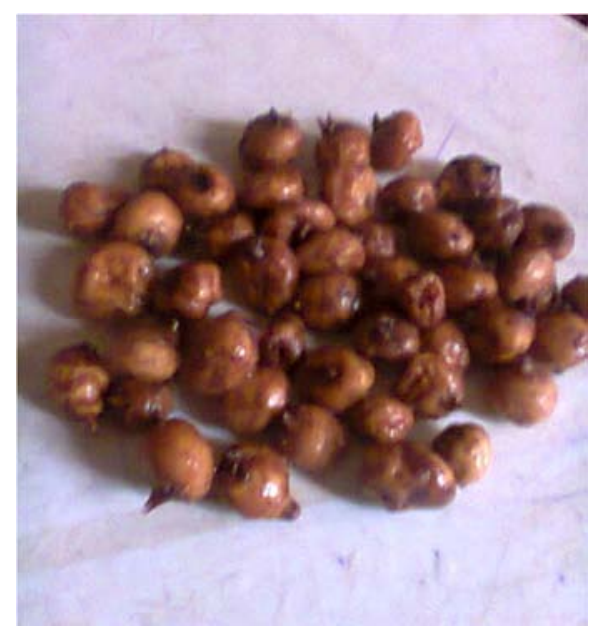

Figure 1. brown variety tiger nut tubers.

\subsection{GC-MS Analysis}

The analysis of the fatty acids in the Cyperusesculentus L. tuber oilsample was done at National Institute of Chemical
Technology (NARICT), Zaria, Nigeria, a Shimadzu QP2010 plus series gas chromatography coupled with Shimadzu QP 2010 plus mass spectroscopy detector (GCMS) system was used. The temperature programmed was set up from $70^{\circ} \mathrm{C}$ to $280^{\circ} \mathrm{C}$. Helium gas was used as carrier gas. The injection volume was $2 \mu \mathrm{L}$ with injection temperature of $250^{\circ} \mathrm{C}$ and a column flow of $1.80 \mathrm{~mL} / \mathrm{min}$ for the GC. For the mass spectroscopy ACQ mode scanner with scan range of 30-700 amu at the speed of 1478 was used. The mass spectra were compared with the NIST 05 mass spectral library [10].

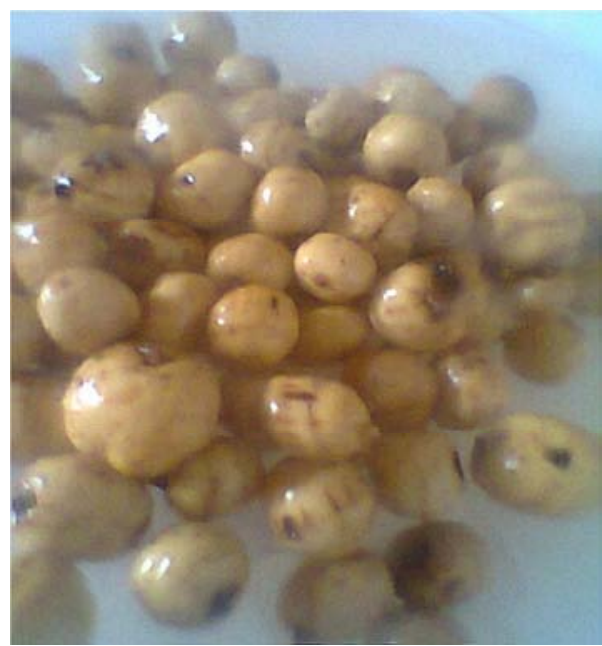

Figure 2. Yellow variety tiger nut tubers.

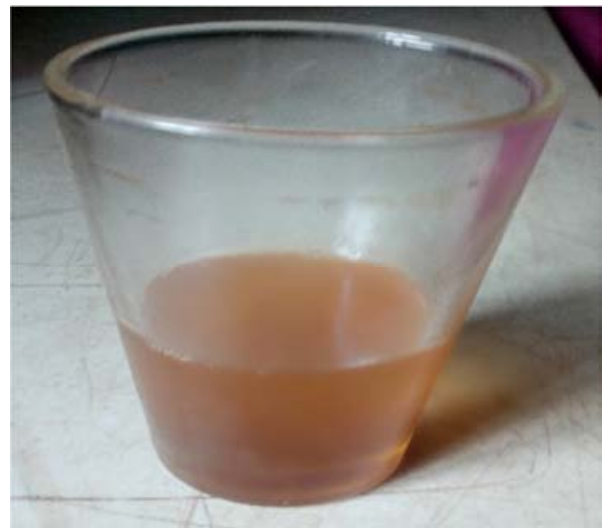

Figure 3. Brown variety tiger nut tuber oil.

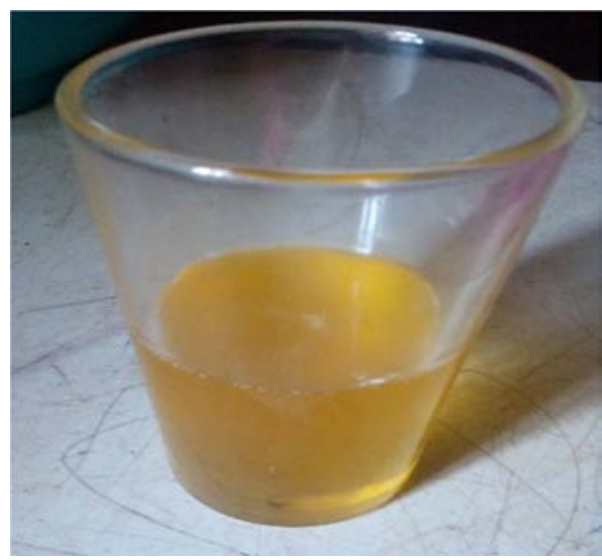

Figure 4. Yellow variety tiger nut tuber oil. 


\section{Results and Discussions}

Table 1. Frequencies, Functional group, Vibrational mode and Intensities of the FT- IR Spectra.

\begin{tabular}{lll}
\hline Brown variety Yellow variety Wave no $\left(\mathbf{c m}^{-1}\right)$ & Wave no $\left(\mathbf{c m}^{-\mathbf{1}}\right)$ Functional group Mode of vibration Intensity \\
\hline 3463.33469 .09 & unsaturated fatty acid / C=O (ester) & Overtone $\mathrm{S}$ \\
2867.282866 .32 & $\mathrm{C}-\mathrm{H}(\mathrm{CH} 2)$ & Stretching (assym) $\mathrm{M}$ \\
$2037.86---$ & $-\mathrm{CNO}$ & Stretching (Symm) $\mathrm{S}$ \\
1742.741743 .71 & $\mathrm{C}=\mathrm{O}($ ester) & Stretching M \\
1450.521449 .55 & $\mathrm{C}-\mathrm{H}(\mathrm{CH} 3)$ & Bending (wagging) S \\
1364.681365 .65 & $-\mathrm{CH} 2-\mathrm{C}$ & Bending (twisting) M \\
718.51718 .51 & cis- olefinic CH2 & Bending (Rocking) S \\
430.14439 .78 & C-O-C & Bending (Rocking) W \\
\hline
\end{tabular}

$\mathrm{W}=$ Weak band, $\mathrm{S}=$ Strong band and $\mathrm{M}=$ moderate band

Table 2. Major fatty acids derived from oil of yellow variety of Cyperus esculentusL.tubers.

\begin{tabular}{lcll}
\hline S/N Name of fatty acid MF MM RI SI\% to T. C. & & \\
\hline Palmitic acid & $\mathrm{C}_{17} \mathrm{H}_{34} \mathrm{O}_{2}$ & 2701878 & 93 \\
Stearic acid & $\mathrm{C}_{18} \mathrm{H}_{36} \mathrm{O}_{2}$ & 2842167 & 91 \\
Margaric acid & $\mathrm{C}_{18} \mathrm{H}_{36} \mathrm{O}_{2}$ & 2702067 & 90 \\
Elaidic acid & $\mathrm{C}_{18} \mathrm{H}_{36} \mathrm{O}_{2}$ & 2962085 & 91 \\
Oleic acid & $\mathrm{C}_{18} \mathrm{H}_{34} \mathrm{O}_{2}$ & 2822178 & 94 \\
Erucic acid & $\mathrm{C}_{22} \mathrm{H}_{42} \mathrm{O}_{2}$ & 3382572 & 92 \\
Behenic acid & $\mathrm{C}_{23} \mathrm{H}_{46} \mathrm{O}_{2}$ & 3542475 & 91 \\
\hline
\end{tabular}

Note: $\mathrm{S} / \mathrm{N}=$ Serial number, M. F. $=$ Molecular formula, M. M. = Molecular weight, $\mathrm{RI}=$ Retention index SI\% $=$ Similarity index, $\mathrm{T} . \mathrm{C} .=$ Target compound

Table 3. Major fatty acids derived from oil of brownvariety of Cyperus esculentus L. tubers.

\begin{tabular}{lcll}
\hline S/N Name of fatty acid MF MM RI SI\% to T.C. & & \\
\hline Palmitic acid & $\mathrm{C}_{17} \mathrm{H}_{34} \mathrm{O}_{2}$ & 2701878 & 92 \\
Stearic acid & $\mathrm{C}_{18} \mathrm{H}_{36} \mathrm{O}_{2}$ & 2842167 & 90 \\
Margaric & $\mathrm{C}_{18} \mathrm{H}_{36} \mathrm{O}_{2}$ & 2702067 & 89 \\
Behenic acid & $\mathrm{C}_{23} \mathrm{H}_{46} \mathrm{O}_{2}$ & 3542475 & 93 \\
Oleic acid & $\mathrm{C}_{18} \mathrm{H}_{34} \mathrm{O}_{2}$ & 2822175 & 94 \\
Erucic acid & $\mathrm{C}_{22} \mathrm{H}_{42} \mathrm{O}_{2}$ & 3382572 & 93 \\
Arachidic acid & $\mathrm{C}_{20} \mathrm{H}_{40} \mathrm{O}_{2}$ & 3122366 & 88 \\
\hline
\end{tabular}

Note: $\mathrm{S} / \mathrm{N}=$ Serial number, M.F.= Molecular formula, M. M. = Molecular weight, RI= Retention index SI\% = Similarity index, T. C. $=$ Target compound.

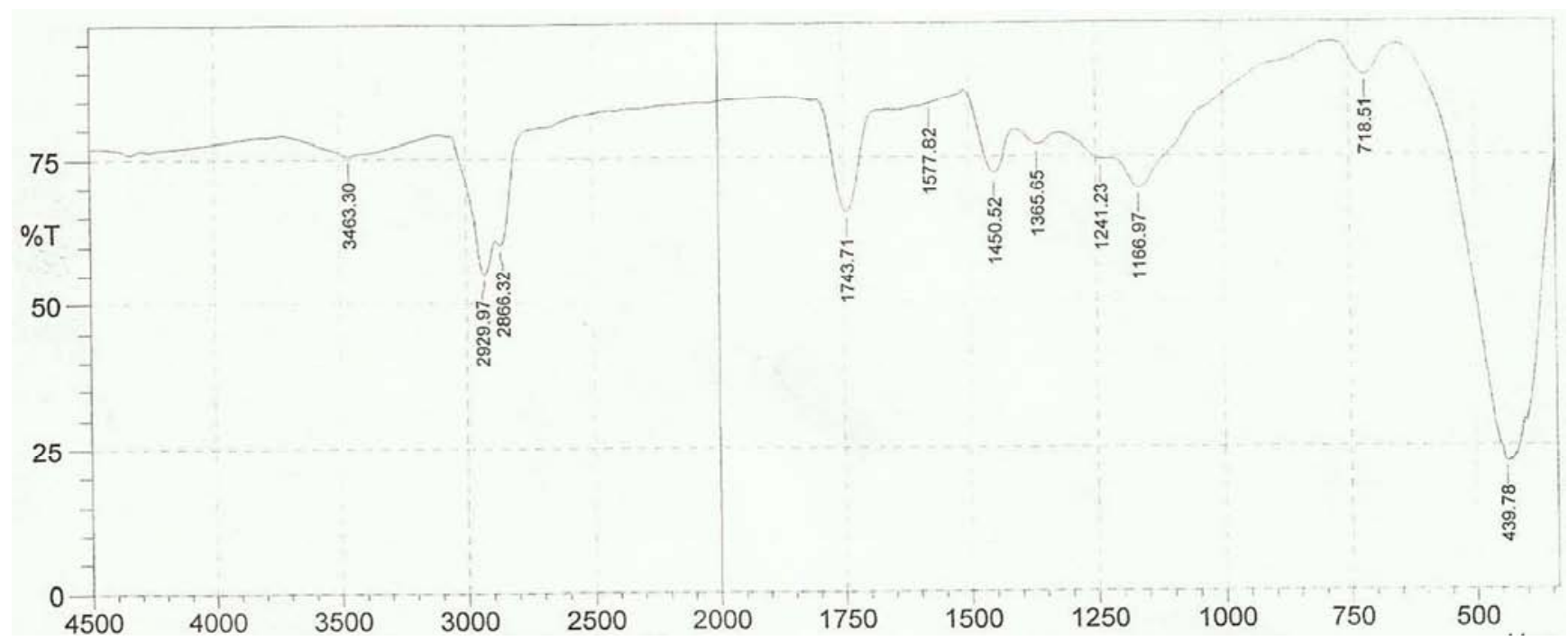

Figure 5. \%T against wave no. plot of typical Infra-Red Spectrum of Brown variety of Cyperusesculentus L. tuber oil. 


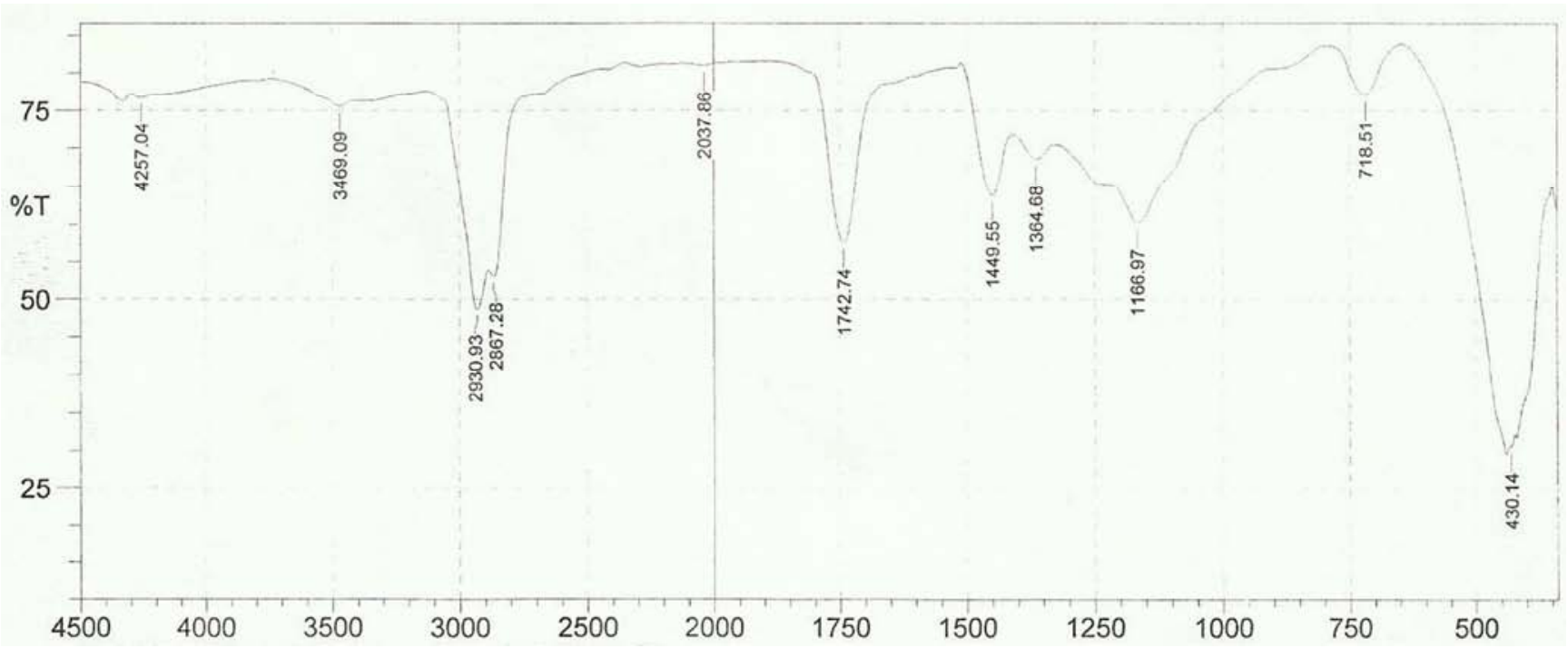

Figure 6. \%T against wave no. plot of typical Infra-Red Spectrum of Yellow variety of Cyperus esculentus L. tuber oil.

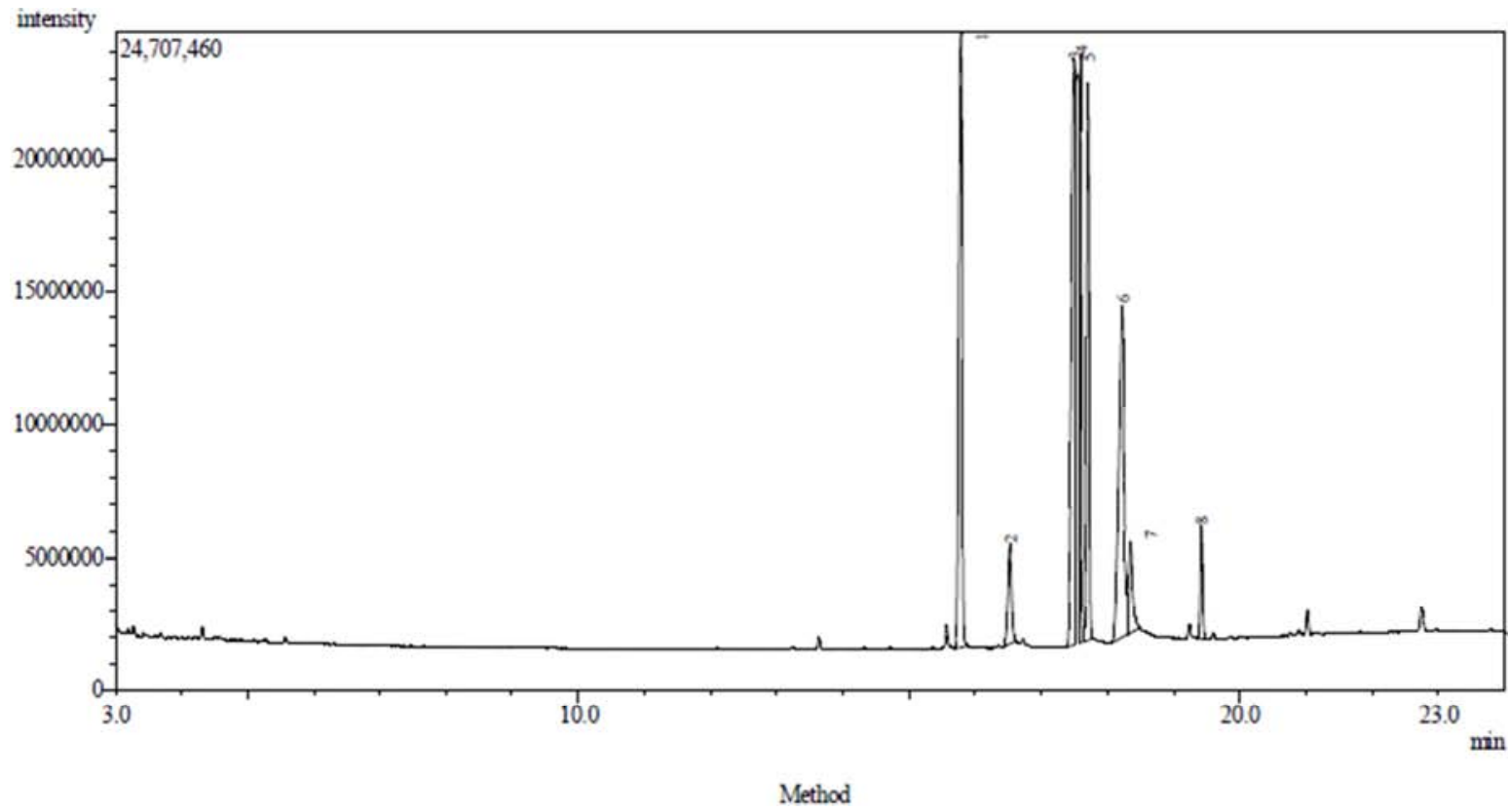

Figure 7. Typical GC-MS total ionic chromatogram (TIC) of hexane extract of brown variety of Cyperusesculentus L. tuber oil.

\section{Hitt:2 Enny.121691 Library:NSTT05.IB}

SI:93 Fonvula:C22H42O2 CAS:112-86-7 MolWeight338 Rethndex:2572

CompName: Erucic acid SS 13-Docosenoic acid. (Z)- SS.delta.13-cis-Docosenoic acid SS cis-13-Docosenocic acid SS (Z)-13-Docosenoic acid SS Prifiac 2990 SS

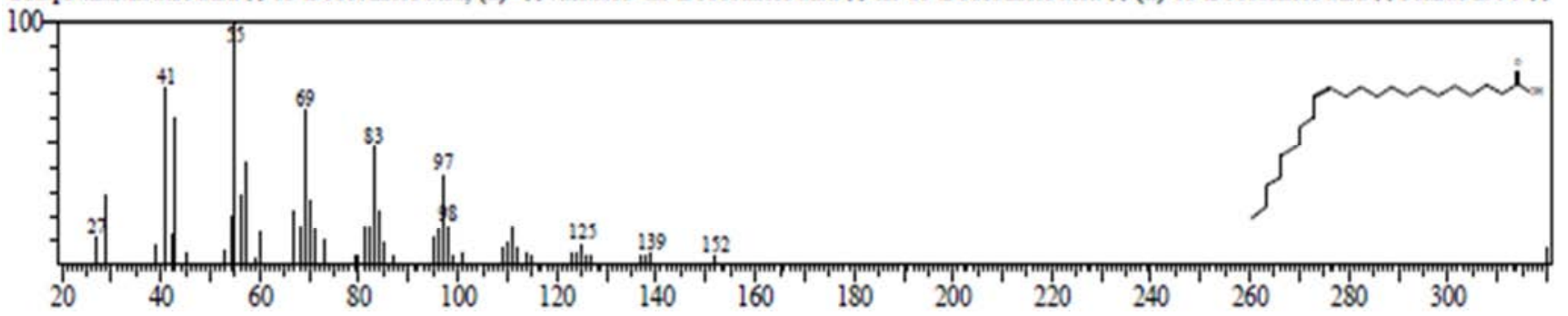


Hitt:5 Entry:22212 Libray:NISTO5;IIB

SI:89 Formula:C17H3402 CAS:506-12-7 MolWeight270 Rethdex:2067

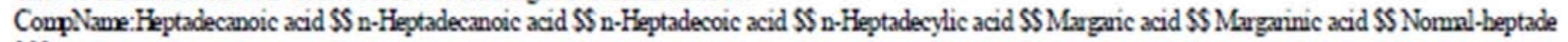

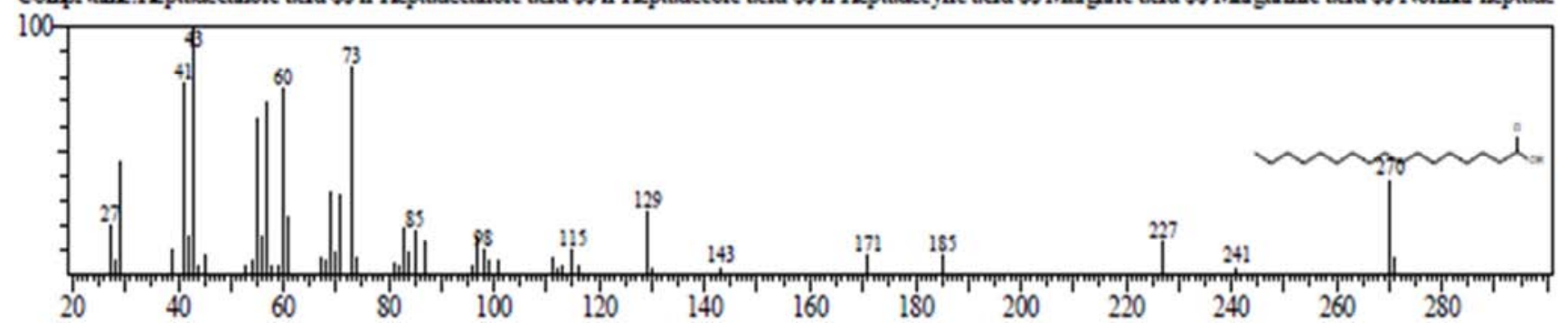

Hitt:5 Entry:108054 Libray:NIST05.IIB

SI:S8 Fonnula:C20H4002 CAS:506-30-9 MolWeight 312 Retindex:2366

CompName:Eicosanoic acid \$S Arachic acid SS Arachidic acid SS Loosanoic acid \$S n-Eicosanoic acid SS Arachidic acid (synthetic) SS

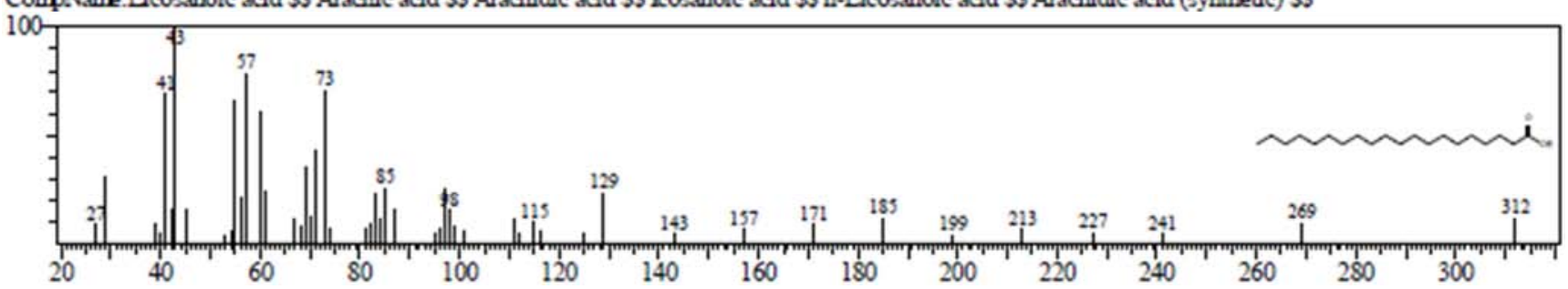

Hitt:1 Entry:25584 Library.NIST05:IMB

SI 93 Formula:C23H4602 CAS:929-77-1 MolWeight 354 Rethdex:2475

CompName:Docosanoic acid, methyl ester SS Behenic acid, methyl ester \$S Methyl behenate SS Methyl docosanoate SS n-Docosanoic acid methyl ester \$S Kem

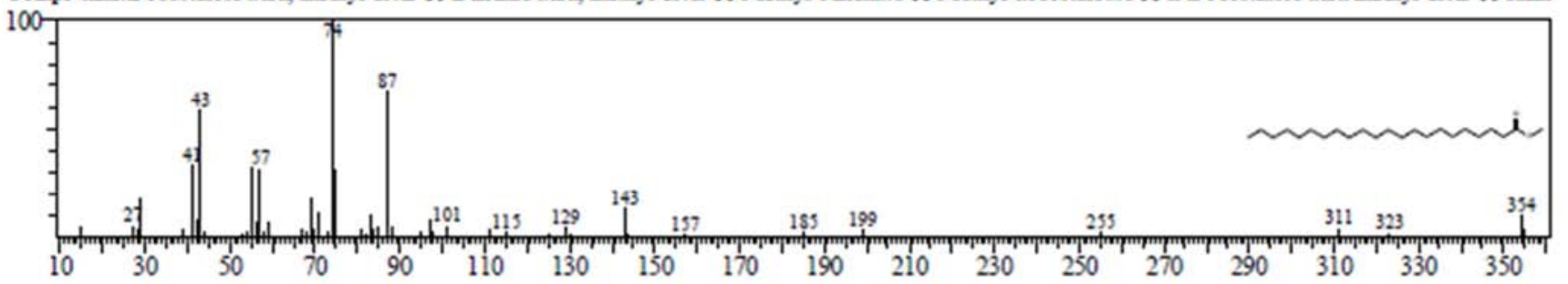

Fit:1 Entry:22869 Library:NISTO5:LIB

SI94 Formula:C18H34O2 CAS:112-80-1 MolWeight282 Rethdex:2175

CompName:Oleic Acid \$S 9-Octadecenoic acid (Z)- \$\$ delta (Sup9)-cis-Oleic acid \$S cis-delta. (Sup9)-Octadecenoic acid \$S cis-Oleic Acid \$\$ cis-9-Octadecer

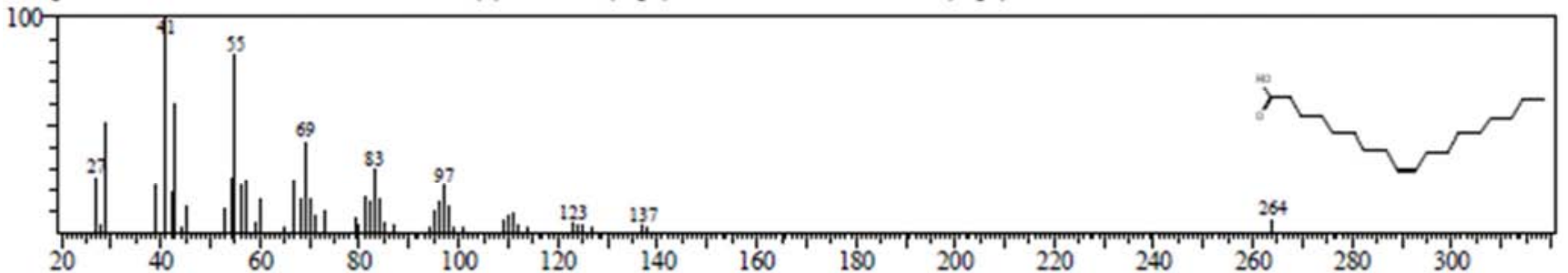

Hitt:5 Entry.22219 Library:NSTO5s.IB

SI:92 Formula:C17H3402 CAS:112-39-0 MolWeight:270 Retindex:1878

CompName:Hexadecanoic acid, methyl ester \$\$ Palmitic acid, methyl ester \$\$n-Hexadecanoic acid methyl ester \$\$ Metholene $2216 \$ \$$ Methyl hexadecanoate \$

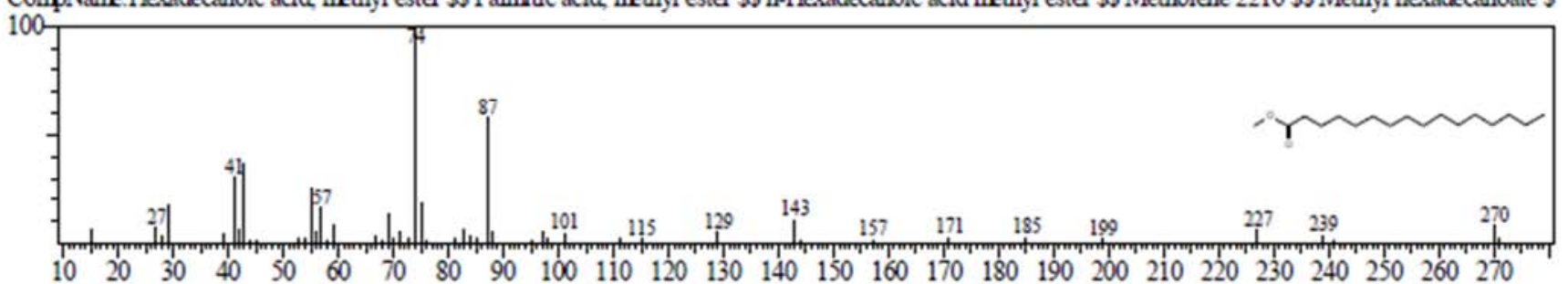


Hitt.3 Entry:22977 Library:NIST05:LIB

SI:90 Fornula:C18H36O2 CAS:57-11-4 MolWeight:284 Retindex:2167

Comp.Name:Octadecanoic acid \$S Stearic acid SS n-Octadecanoic acid \$S Humko Industrene R SS Hutrofol Acid 150 \$S Hystrene S-97 \$S Hystrene T-70 \$S Hy:

100

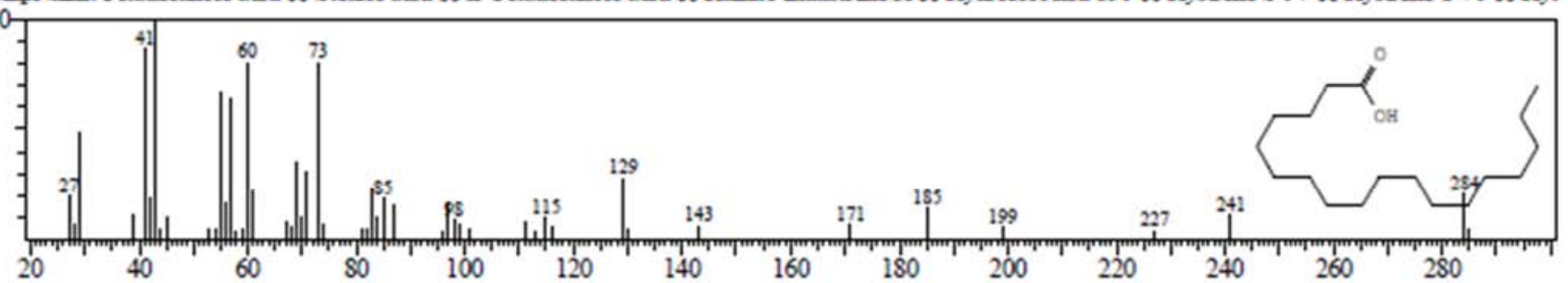

Figure 8. GC-MS Fragments of hexane extract of brown variety of Cyperus esculentus L. tuber oil.

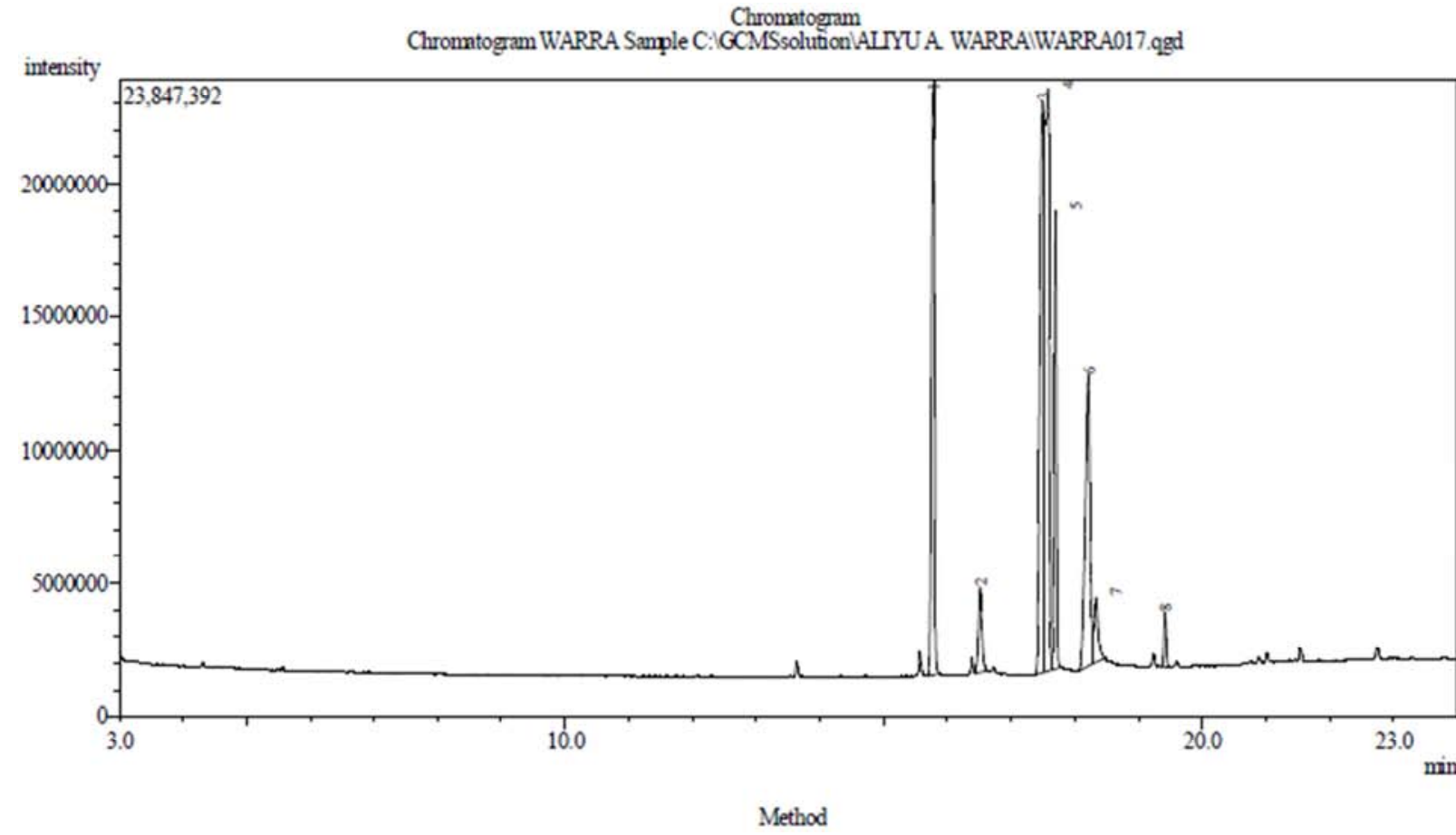

Figure 9. Typical GC-MS total ionic chromatogram (TIC) of hexane extract of Yellow variety of Cyperus esculentus L. tuber oil.

Hitł:5 Entry.22219 Library:NISTO5s.LIB

SI:93 Formula:C17H3402 CAS:112-39-0 MolWeight:270 Rethdex:1878

CompName: Hexadecanoic acid, methyl ester $\$ \$$ Palmitic acid, methyl ester $\$ \$$ n-Hexadecanoic acid methyl ester $\$ \$$ Metholene $2216 \$ \$$ Methyl hexadecanoate $\$$

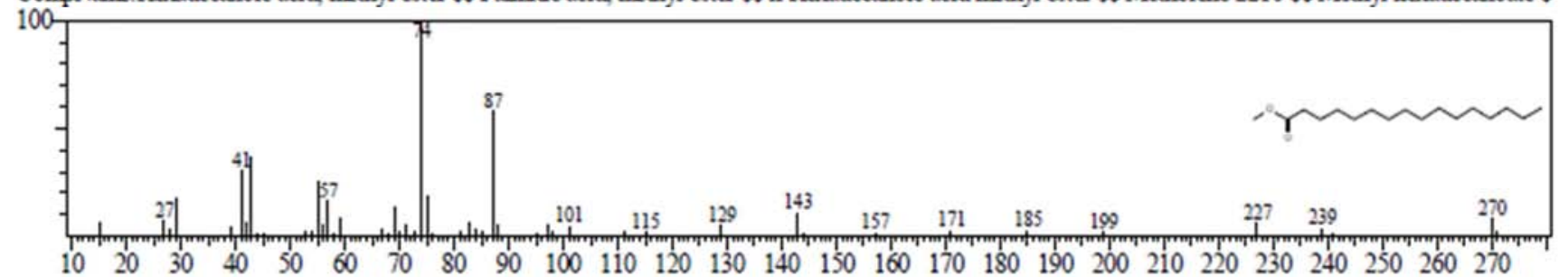

Hit\#:2 Entry.22977 Library:NISTO5s.LB

SI:91 Formula:C18H3602 CAS:57-11-4 MolWeight:284 Retindex:2167

CompName:Octadecanoic acid \$S Stearic acid \$S n-Octadecanoic acid \$S Humko Industrene R SS Hydrofol Acid 150 \$S Hystrene S-97 \$S Hystrene T-70 \$\$ Hy:

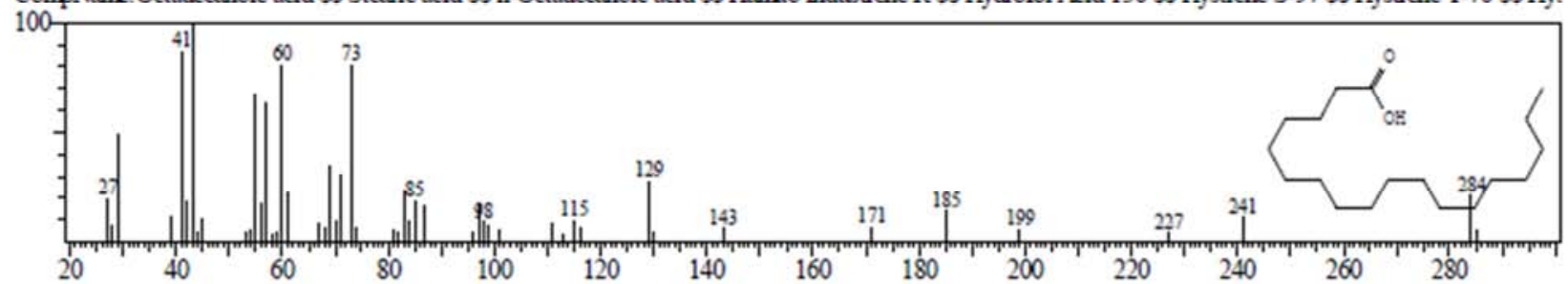


SI:90 Formula:C17H3402 CAS:506-12-7 MolWeight:270 Rethndex:2067

CompName:Heptadecanoic acid $\$ \$ \mathrm{n}$-Heptadecanoic acid $\$ \$ \mathrm{n}$-Heptadecoic acid $\$ \$ \mathrm{n}$-Heptadecylic acid $\$ \$$ Mrgaric acid $\$ \$$ Margarinic acid $\$ \$$ Norml-heptade

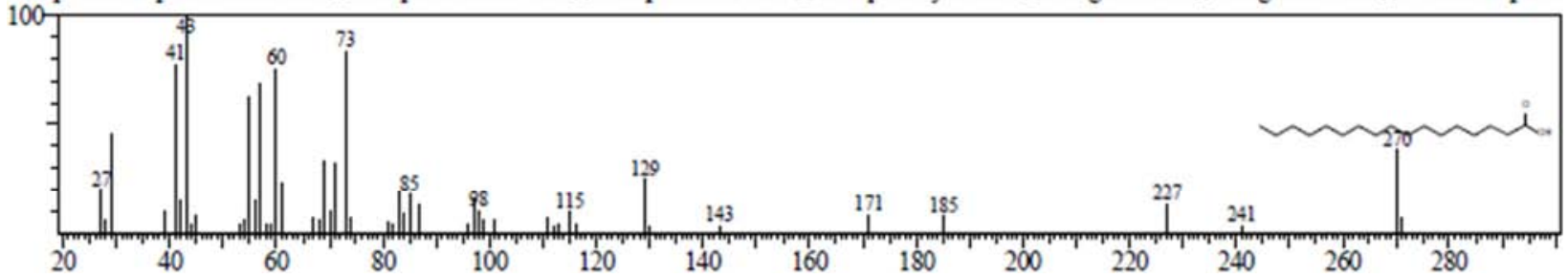

Hitt:3 Entry:23570 Library:NISTO5s.LB

SI:91 Fommla C19H3602 CAS:1937-62-8 MolWeight:296 Retindex:2085

CompName9-Octadecenoic acid, methyl ester, (E)- \$S Elaidic acid, methyl ester \$SMethyl elaidate \$SMethyl trans-9-octadecenoate \$S (E)-9-0ctadecenoic aci

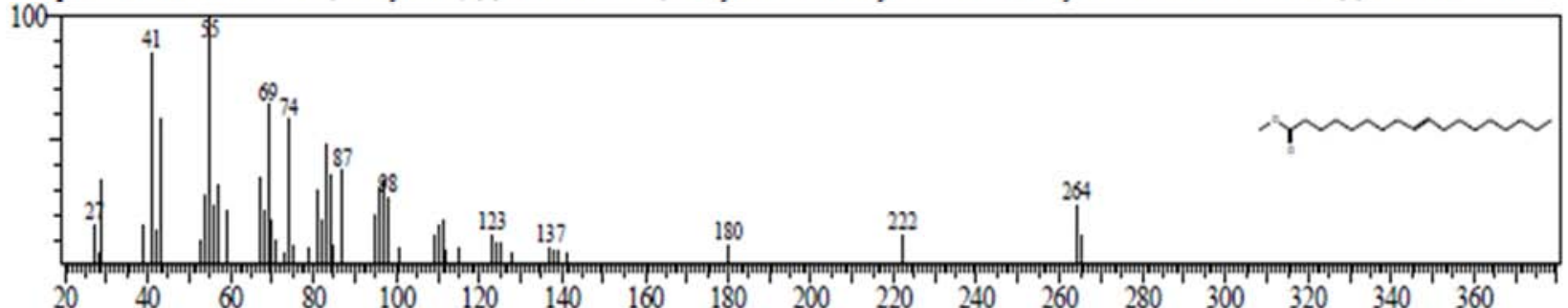

Hitt: 1 Entry:22869 Library:NISTO5s.LIB

SI:94 Formula:C18H3402 CAS:112-S0-1 MolWeight:282 Retindex:2175

CompName:Oleic Acid \$S 9-Octadecenoic acid (Z)- SS delta(Sup9)-cis-Oleic acid SS cis-delta.(Sup9)-Octadecenoic acid SS cis-Oleic Acid SS cis-9-Octadecer

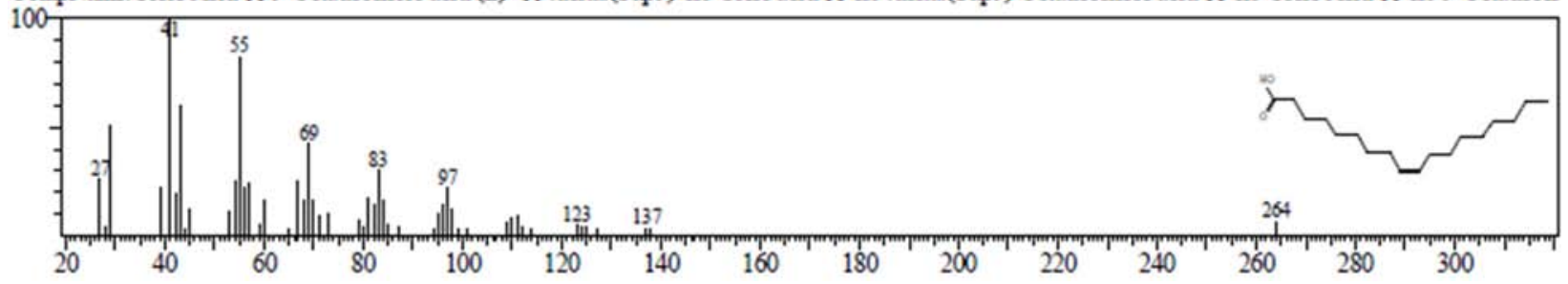

Hitt: 2 Entry:121691 Library.NIST05.LB

SI:92 Formula:C22H42O2 CAS:112-86-7 MolWeight 338 Retindex:2572

ConpName:Erucic acid \$S 13-Docosenoic acid, (Z)- \$S .delta.13-cis-Docosenoic acid \$S cis-13-Docosenoic acid SS (Z)-13-Docosenoic acid \$S Prifrac 2990 \$S

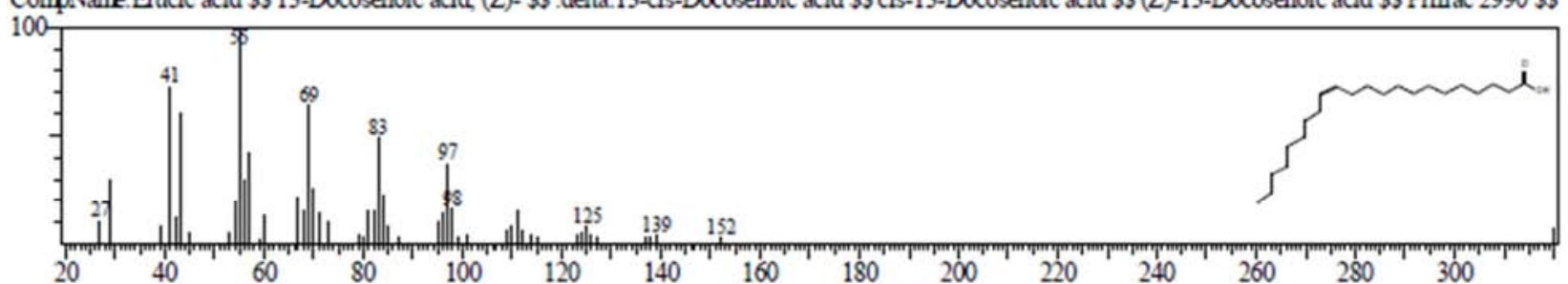

Hitt:3 Entry:25584 Library:NSTO5s.LB

SI:91 Fomvla C23H46O2 CAS:929-77-1 MolWeight 354 Rethidex:2475

CompName:Docosanoic acid, methyl ester \$\$ Behenic acid, methyl ester \$\$ Methyl behenate \$\$ Methyl docosanoate \$S n-Docosanoic acid methyl ester \$\$ Kem

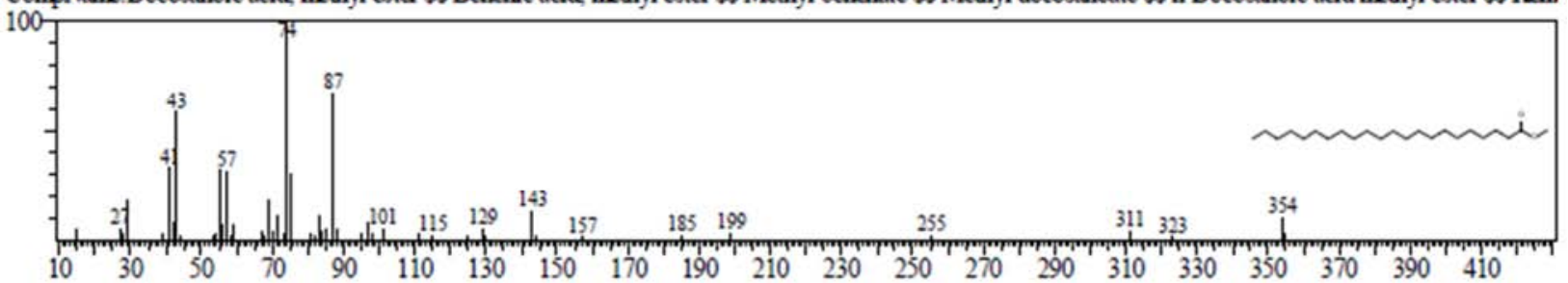

Figure 10. GC-MS Fragments of hexane extract of yellow variety of Cyperus esculentus L. tuber oil.

\section{Discussion}

The following major fatty acids were qualitatively identified form the GC-MS analysis; Palmitic acida natural saturated acid, present in plants, animals, and microorganisms [11]. It is among the fatty acids that isusedin high concentration in cosmetics [12]. Stearic acida saturated fatty acid with an 18-carbon chain and the IUPAC name octadecanoic acid was found, Stearic acid is mainly used in 
the production of detergents, soaps, and cosmetics such as shampoos and shaving cream products. Soaps are not made directly from stearic acid, but indirectly by saponification of triglycerides consisting of stearic acid esters. Esters of stearic acid with ethylene glycol, glycol stearate, and glycol distearate are used to produce a pearly effect in shampoos, soaps, and other cosmetic products. They are added to the product in molten form and allowed to crystallize under controlled conditions. Detergents are obtained from amides and quaternary alkylammonium derivatives of stearic acid. Surfactants, cosmetics and personal hygiene products are in fact prospects of stearic acid [13]. Heptadecanoic acid or margaric acid is a saturated fatty acid was also detected. Oleic Acid's presence makes it a great moisturizer, and a number of cosmetic companies add it to lotions and soaps in order to boost their ability to nourish the skin [14] Behenic acid detected is often used to give hair conditioners and moisturizers their smoothing properties. Also used as antifoam in the manufacturing of detergents [15]. Arachidic acid also called eicosanoic acid is a saturated fatty acid was detected. It is found in appreciable quantities only in some vegetable fats and oils where it occurs as glycerol ester [16]. Erucic acid was also found, products produced using erucic acid include cosmetics [17].

The FT-IR bands of $3469.09 \mathrm{~cm}^{-1}, 3463.3 \mathrm{~cm}^{-1}$ observed in yellow and brown tiger nut oil respectively are the region of unsaturated fatty acid. The asymmetrical and symmetrical modes of vibration of $-\mathrm{CH}_{2}$-exhibit very strong and sharp bands at $2867.28 \mathrm{~cm}^{-1}, 2037.86 \mathrm{~cm}^{-1}$ and $2866.32 \mathrm{~cm}^{-1}$ for yellow and brown tiger nut oil. The band at $1742.74 \mathrm{~cm}^{-1}$ and $1743.71 \mathrm{~cm}^{-1}$ is very strong and sharp band due to ester carbonyl functional group of the triglycerides i.e $\mathrm{C}=\mathrm{O}$ stretching vibrations no absorption around $1710 \mathrm{~cm}^{-1}$ this shows that the fatty acids is exclusively in ester forms. [18]. The bending vibrations of the $\mathrm{CH}_{2}$ and $\mathrm{CH}_{3}$ aliphatic groups, $\left(\mathrm{C}-\mathrm{CO}-\mathrm{O}-\right.$ and $\left.\mathrm{O}-\mathrm{CH}_{2}-\mathrm{C}\right)$ and the in-plane bending vibration of $\mathrm{CH}$ cis-olefinic groups are seen at $1449.55 \mathrm{~cm}^{-1}$, $1364 \mathrm{~cm}^{-1}$ and $1450.52 \mathrm{~cm}^{-1}, 1365.65 \mathrm{~cm}^{-1}$ for yellow and brown tiger nut oil respectively. The vibration frequency at, $1166.97 \mathrm{~cm}^{-1}$ for brown tiger nut oil and yellow tiger nut oil is finger print of the stretching vibration of the $\mathrm{C}-\mathrm{O}$ ester group. The frequencies of the in-and out-of plane rocking of the cis-olefinic $\mathrm{CH}_{2}$ group are at $718.51 \mathrm{~cm}^{-1}$ for the brown and yellow tiger nut. The observed differences in frequency positions of the ester carbonyl, and the inactivity or absence of some in-plane bending are attributed to the variation in fatty acids composition, chain length, degree and position of double bonds in the triacylglycerols [19]. However, polymeric applications of quality characterized plants oils in general found useful in polymer preparations. A plant oil with a metathesis catalyst produces cyclohexadiene (CHD), which can then be converted to other monomers through isomerization or polymerized to mimic petroleum-based polymers. The preparation of cyclohexadiene (CHD) can be performed with little to no plant oil purification, minimal catalyst loading, no organic solvents, and simple product recovery by distillation. These monomers can be used to supplement or substitute petroleum-based monomers traditionally used in the preparation of polymeric materials [20].

\section{Conclusion}

The results of FT-IR and fatty acid composition of oil from two varieties of tiger nut (Cyperus esculentus L.) tubers through GC-MS analysis indicated that there is no different as such in the two varieties and they are suitable for industrial production of cosmetic and polymeric products.

\section{References}

[1] Bamishaiye, E. I. and Bamishaiye, O. M (2011). Tiger nut: as a plant, its derivatives and benefits. African Journal of Food, Agriculture, Nutrition and Development.

[2] Jansen, L. L. 1971.Morphology and photoperiodic responses of yellow nutsedge (Cyperusesculentus). Weed Science 19:210-219.

[3] Osagie, A. U and Eka, O. U. (1998). Nutritional quality of plant foods. Post-Harvest Research Unit, University of Benin, Benin City, Nigeria, pp $15-31$.

[4] Oyedele O. A., Oladipo I. O. Adebayo A. O (2015). Investigation into Edible and Non-edibleOil Potentials of Tiger Nut (Cyperusesculentus) Grown in Nigeria. Global Journal ofEngineering Design and Technology. (4):20-24.

[5] Warra, A. A (2014).Quality Characteristics of oil from Brown and Yellow CyperusesculentusL. Tubers. Research and Reviews: Journal of Botanical Sciences.3 (1):23-26.

[6] Ezeh, O, Gordon, M. H., Niranjan, K (2014). Tiger nut oil (Cyperus esculentus L.): A review of its composition and physico - chemical properties. European Journal of Lipid Science and Technology. 116: 1-11.

[7] El-Naggar, E. A (2016). Physicochemical Characteristics of Tiger Nut Tuber (Cyperus esculentus Lam) Oil. Middle East Journal of Applied Sciences. 6 (4): 003-1011.

[8] Adewuyi, A., Otuechere, C. A., Oteglolade, Z. O., Bankole, O., Unuabonah, E. I (2015). Evaluation of the safety profile and antioxidant activity of fatty hydroxamic acid from underutilized seed oil of Cyperus esculentus. Journal of Acute Disease.4 (3): 230-235.

[9] Sidohounde, A., Nonviho, G., Djenontin, S. T., Agbangnan, P., Paris, C., and Dominique C. K. Sohounhloue, D. C. K (2014). Physico-Chemical Characterization of Vegetable Oil and Defatted Meal from Two Varieties of Cyperus esculentus from Benin. Chemistry Journal. 4 (1):1-7.

[10] NIST (2012). GC-MS NIST Library Information Manual. 2012.

[11] Gunstone, F D. Harwood, J. L. Albert J. Dijkstra, A. J. (2007). The lipid handbook. Taylor \& Francis Group, LLC. p. 4.

[12] Liebert, MA (1987). Final Report on the Safety Assessment of Oleic Acid, Laurie Acid, PalmiticAcid, Myristic Acid, and Stearic Acid. Journal of the American College of Toxicology. 6 (3):321-402. 
[13] Gunstone, F. D (2004). The chemistry of oils and fats sources, composition, properties and uses. Blackwell Publishing Ltd, UK. 1987, p 54.

[14] PubChem. 2014. Elaidic acid. Accessed 12/12/2014 at pubchem.ncbi.nlm.nih.gov/compound/ Elaidic acid.

[15] Rulis, A (2001). Behenic Acid Notification. Flamm Associates. Vero Beach. pp 3-4.

[16] Okoh, C. C, Min, D. B (2008). Food lipids: Chemistry, Nutrition, and Biotechnology. $3^{\text {rd }}$ ed

[17] WiseGEEK Erucic acid. 2015. Information on http://www.wisegeek.com/what-is-erucic-acid.htm
[18] Silverstein, R.; Webster, F.; Kiemle, D. Spectrometric Identification of Organic Compounds; John Wiley \& Sons, Inc.: New York, NY, USA, 2005.

[19] Guillen, M. D. and Cabo, N. (1997). Characterization of edible oils and lard by Fourier transform infrared spectroscopy. Relationships between composition and frequency of concrete bands in the fingerprint region. J. of the Am. Oil Chem. Soc. 74 (10): 1281-1286.

[20] Office of Technology Management-The Pennsylvania State University. Plant Oil Based Polymers. Available from https://www.research.psu.edu/sites/default/files/plant-oilbased-polymers.pdf Accessed 28 May, 2017. 